\title{
Effect of Silver Nitrate and Epidermal Growth Factor on Nonhealing Tympanic Membrane Perforations: A Randomized Controlled Study
}

\author{
Vikram Kemmannu Bhat ${ }^{1}$ \\ 1Department of Otolaryngology, Head and Neck Surgery, Karnataka \\ Institute of Medical Sciences, Hubli, Karnataka, India \\ ${ }^{2}$ Department of Otolaryngology, Head and Neck Surgery, Ascent \\ ENT Hospital, Perinthalmanna, Kerala, India
}

\author{
Vidyashree Kalapurada Mathad ${ }^{1}$
}

\begin{abstract}
Address for correspondence Vikram Kemmannu Bhat, MS, DNB, MNAMS, PhD, Department of Otolaryngology, Head and Neck Surgery, Karnataka Institute of Medical Sciences, Vidyanagar, Hubli 580021, Karnataka, India (e-mail: vikram.ent@gmail.com).
\end{abstract}

\begin{abstract}
Keywords

- epidermal growth factor

- silver nitrate

- tympanic membrane perforation

- chronic otitis media

Introduction Most tympanic membrane perforations in chronic otitis media require surgical myringoplasty for closure. This study aimed to find out a simple nonsurgical outpatient procedure to close these perforations that could reduce the hospital stay, medical cost, and morbidity in these patients.

Materials and Methods The study was conducted in a tertiary referral hospital in a single-blind randomized controlled trial design with two groups, each with a sample size of 40 ears. Only small-size central nonhealing traumatic and chronic otitis media perforations were recruited. Pure tone audiometry and otomicroscopy were performed in all eligible patients who consented to take part in the study. Group 1 was treated with silver nitrate chemical cautery alone. Group 2 received epidermal growth factor gel application in addition to chemical cautery. Both the groups were followed up for a minimum period of 3 months. The same investigations were performed during follow-up.

Results and Observations The outcome was considered a success whether there was closure of perforation or reduction in the size of perforation. The success rate of these nonhealing perforations was found to be significantly higher in group 2 (71.42\%) than in group 1 (47.36\%). Hearing gain was observed in closed perforations of both the groups.

Conclusion Epidermal growth factor application enhances the healing effect of silver nitrate in small nonhealing tympanic membrane perforations. The encouraging results of epidermal growth factor have vast applications in improving outcomes of surgical myringoplasty and treatment of residual perforations remaining after the same.
\end{abstract}

\section{Introduction}

Chronic otitis media (COM) is a widespread disease of the developing countries, especially the rural areas. It is one of the most common causes for hearing loss that mainly results due to tympanic membrane perforation.

Majority of tympanic membrane perforations in COM require tympanoplasty for closure. Hospital expenditure associated with tympanoplasty has compelled investigators to search for less expensive, simple nonsurgical methods. Epidermal growth factor (EGF) is an important modulator of cell growth, and its role in normal wound healing is well documented. EGF receptors have been identified in tympanic membrane of different animals. The ability of EGF to promote healing of tympanic membrane perforations has recently been shown in experimental animals, when applied topically. 
This study aimed to compare the effect of EGF on chronic nonhealing tympanic membrane perforations due to trauma or COM when used topically after conventional silver nitrate cautery.

\section{Materials and Methods}

The study was conducted in a tertiary referral public hospital in a span of 1 year after obtaining the necessary clearance from the institutional ethics review board. Every consecutive eligible patient fulfilling the inclusion and exclusion criteria was recruited into the study. This was a single-blind randomized controlled trial (RCT). There were two groups in the study, and only small-size perforations were included. Group 1 received silver nitrate $\left(\mathrm{AgNO}_{3}\right)$ application only, whereas group 2 received EGF gel application in addition to $\mathrm{AgNO}_{3}$.

\section{Inclusion Criteria}

- Subjects having inactive mucosal type of COM with nonhealing perforation.

- Traumatic perforation, not healing for at least 1 month.

- Dry post tympanoplasty residual perforations.

- Age more than 14 years and less than 65 years.

\section{Exclusion Criteria}

- Active predisposing disease focus in the nose or throat.

\section{Methodology}

Prospective study candidates were examined and investigated in the ENT (ear-nose-throat) outpatient clinic to confirm the eligibility. A full valid written consent was taken from all eligible candidates. A pure tone audiometry to record the hearing loss, a diagnostic nasal endoscopy to rule out predisposing focus in the nose, and an otomicroscopy to examine the perforation were performed. The perforation size was approximately assessed using a graduated (maximum $5 \mathrm{~mm}$ ) right-angled fine aural probe.

\section{Randomization}

Eighty ears were randomized to one of the two treatment groups. Group 1 (silver nitrate cautery alone) included 38 ears and group 2 (silver nitrate cautery + topical EGF gel) included 42 ears. A random sequence of the numbers 1 and 2 was generated using RALLOC computer software. Number 1 corresponded to silver nitrate cautery alone (i.e., group 1) and number 2 to silver nitrate cautery + topical EGF gel application (i.e., group 2). Patients underwent one of the two treatment options as per their computer-generated random allocation number.

\section{Allocation Concealment}

All computer-generated random numbers were carefully marked into a paper slip. This paper slip was then sealed in an opaque, dark envelope. The numbered envelopes were collected together and tagged. These steps were performed by a neutral observer who was not involved in the study.

\section{Procedure}

Even though the procedures in both the groups were performed by two experienced surgeons, the steps were standardized and hence essentially the same.

\section{Treatment Procedure and Intervention in Group One}

- All the treatment procedures were performed under local anesthesia by applying 4\% lignocaine drops to the ear 10 minutes before the procedure.

- Under otomicroscopic vision the margins of tympanic membrane perforations were cauterized using a probe with silver nitrate solution at its tip. The solution was prepared by dissolving $2 \mathrm{~g}$ of silver nitrate crystals in $2 \mathrm{~mL}$ of sterile distilled water.

- A thorough normal saline wash was given, and the remaining silver nitrate solution was suctioned out from the middle ear and external auditory canal.

- A small piece of dry Gel foam (absorbable gelatin sponge; Virchow Biotech Private Ltd., Rangareddy District, Andhra Pradesh, India) was kept over the tympanic membrane for support.

- The external auditory canal was packed with a small piece of povidone iodine tulle. Antibiotic ointment-soaked cotton ball was kept over the tulle externally.

\section{Treatment Procedure and Intervention in Group Two}

After performing silver nitrate cauterization and saline wash (i.e., steps 1-3 of group 1), $2 \mathrm{~g}$ of $150 \mu \mathrm{g} / \mathrm{g}$ recombinant human EGF gel (Eugraf 150 gel, Bharat Biotech International Ltd., Genome Valley, Turkapally, Hyderabad, India; marketed by Lupin Ltd., Mumbai, India) was applied directly over the tympanic membrane perforation, and a small piece of dry Gel foam was kept over it. The external auditory canal was packed with a small piece of povidone iodine tulle. Antibiotic ointment-soaked cotton ball was kept over the tulle externally.

All patients in both the groups were treated with same medications, that is, amoxicillin clavulanic acid (625 mg) tablets twice a day for 5 days, levocetirizine $(5 \mathrm{mg})+$ phenylephrine (60 mg) tablets at night for 15 days, and analgesic tablets for 3 days.

\section{Follow-up Visits}

Patients were followed up in first, second, and third months after the procedure in ENT outpatient clinic. Packs were removed from the ear at the first visit. During each follow-up, the patient underwent otomicroscopy to access the perforation size, presence of discharge, to rule out complications. A pure tone audiometry was performed at the third visit in patients whose perforation was closed. Closure of the perforation and decrease in perforation size were the primary outcomes measured. Hearing gain and complications were the secondary outcomes considered.

The study was completed and recorded in accordance with the revised CONSORT (consolidated standards of reporting trials) statement guidelines ( - Fig. 1) for evaluating the structure and analysis of RCTs. ${ }^{1}$ 


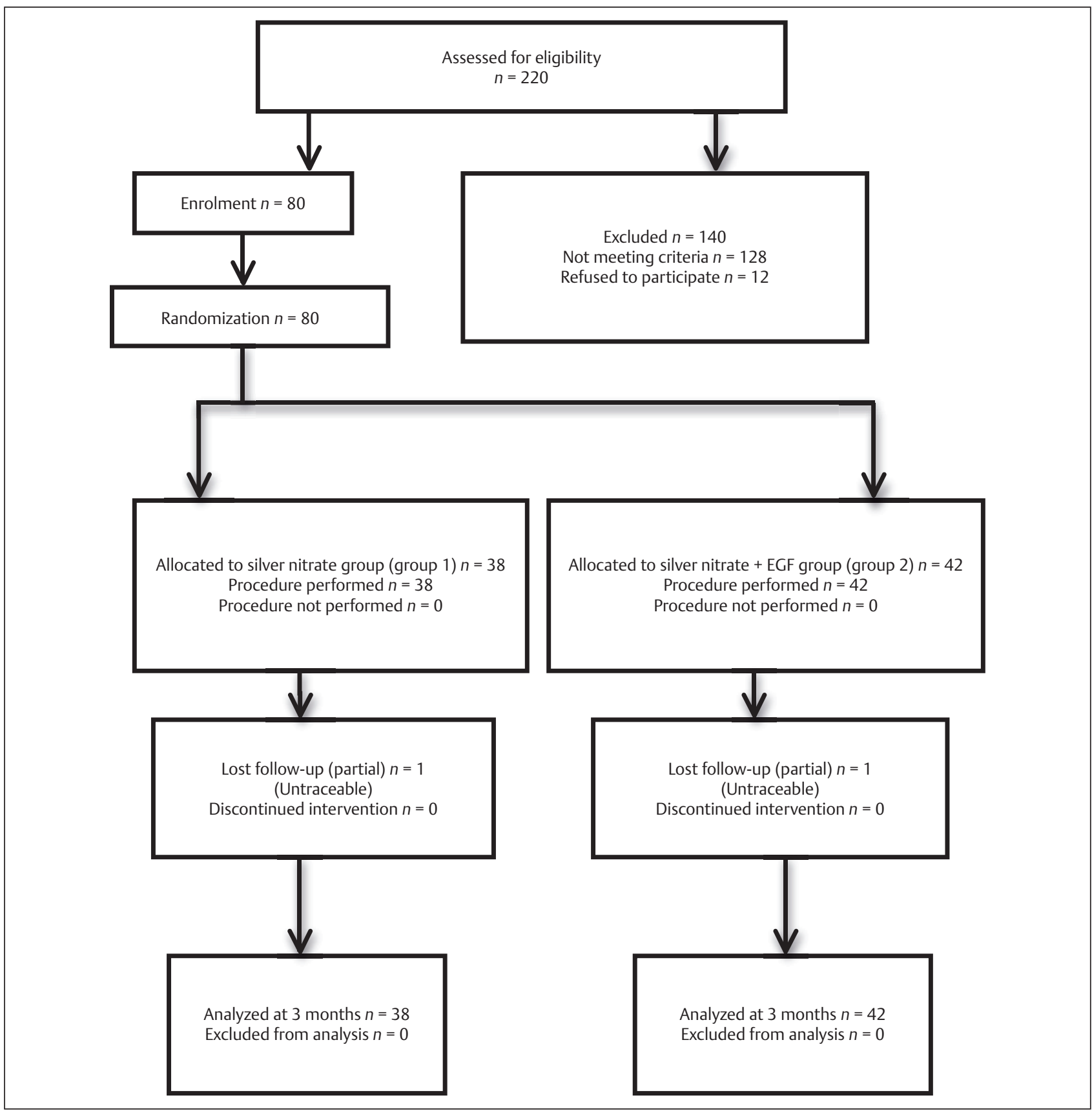

Fig. 1 CONSORT flowchart showing study details. EGF, epidermal growth factor.

\section{Observation and Results}

Eighty patients, 38 in $\mathrm{AgNO}_{3}$ (group 1) and 42 in $\mathrm{AgNO}_{3}+\mathrm{EGF}$ (group 2) who fulfilled the inclusion and exclusion criteria, were recruited into the study.

The various observations made in this study are presented below

\section{- Age distribution of the study population.}

The age group ranged from 14 to 65 years. Mean age in study population was $33.94 \pm 14.19$. In group $1\left(\mathrm{AgNO}_{3}\right)$, mean age was $38 \pm 33.11$ and in group $2\left(\mathrm{AgNO}_{3}+\mathrm{EGF}\right)$ it was $34.69 \pm 14.70$. The mean age difference in groups 1 and 2 was not found to be statistically significant $(t=0.498$, d.f. $=77.9, p=0.62)$. Hence the two groups were similar and comparable.

- Distribution of cases according to diagnosis.

The distribution of the cases according to the diagnosis is as shown in (-Fig. 2).

- Distribution of cases according to treatment outcome.

The outcome was considered to be success if there was complete closure or reduction in the perforation size ( - Table 1). It was considered as failure if there was persistence of the same size or increase in the perforation size. Eighteen and 30 cases either completely closed or reduced in size (success) in 


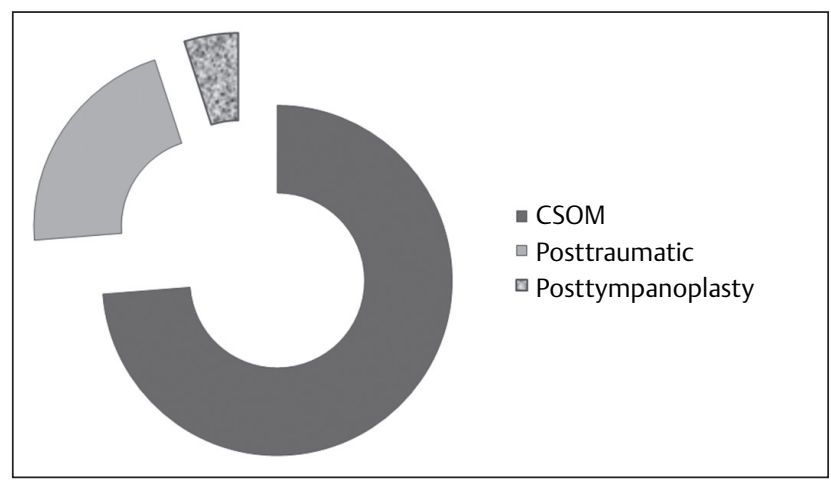

Fig. 2 Distribution of cases according to diagnosis. CSOM, chronic suppurative otitis media.

Table 1 Distribution of successful cases according to treatment outcome

\begin{tabular}{|l|l|l|l|}
\hline $\begin{array}{l}\text { Treatment } \\
\text { group }\end{array}$ & $\begin{array}{l}\text { Number of } \\
\text { cases that } \\
\text { improved }\end{array}$ & $\begin{array}{l}\text { Perforations } \\
\text { that closed } \\
\text { completely }\end{array}$ & $\begin{array}{l}\text { Perforations } \\
\text { that reduced } \\
\text { in size }\end{array}$ \\
\hline Group 1 & 18 & 15 & 3 \\
\hline$(n=38)$ & $(47.36 \%)$ & $(83.3 \%)$ & $(16.66 \%)$ \\
\hline Group 2 & 30 & 26 & 4 \\
\hline$(n=42)$ & $(71.42 \%)$ & $(86.6 \%)$ & $(13.33 \%)$ \\
\hline
\end{tabular}

groups 1 and 2, respectively. The success rate was found to be significantly higher in group 2 (30 [73.1\%]) compared with group $1(18[48.6 \%])\left(\chi^{2}\right.$ value $=4.94$, d.f. $=1, p<0.026$ at $95 \%$ confidence interval).

- Hearing gain in the perforations that closed.

The hearing gain was assessed in those cases that closed completely after 3 months in both the groups. There was hearing gain in both the groups (73.3\% in group 1 and $88.4 \%$ in group 2), which was not found to be significant statistically $\left(\chi^{2}\right.$ value $=1.54$, d.f. $\left.=1, p=0.215\right)$.

\section{- Occurrence of complications in the groups.}

Few complications observed during the study were otitis externa, otomycosis, and tympanosclerosis. They were comparable in both the groups and not found to be significant statistically $\left(\chi^{2}\right.$ value $=0.940$, d.f. $\left.=1, p=0.332\right)$.

\section{Discussion}

COM is a common disease that presents itself in various forms in different parts of the world. The burden of disease due to COM or trauma continues to be high in spite of the advances in health care. Nonhealing perforations are particularly a problem with COM mucosal type due to their potential to undergo changes, such as granulation and cholesteatoma formation, ossicular necrosis, tympanosclerosis, hearing loss, and also recurrent ear discharge. Because of high medical cost, long hospital stays, or more number of cases, it has become difficult to treat all these cases by surgical myringoplasty. This study attempted to find out a simple nonsurgical OPD procedure to close the tympanic membrane perforations caused by trauma or COM, which could reduce the hospital stay, medical cost, and morbidity. Several studies have been conducted in the past on animals and human beings pertaining to the effect of EGF on tympanic membrane perforations (-Table 2). However, to the best of our knowledge, its effect on nonhealing tympanic membrane perforations of COM and trauma in human beings in the design of an RCT has not been reported in literature before.

The confounding factors of predisposing disease foci in the nose and throat were treated either medically or surgically before recruiting the case into the study.

Even though silver nitrate was already being used to close small perforations, whether the added effect of EGF on such nonhealing perforations would lead to higher success rates is not known. EGF could not be tested against a placebo such as a saline solution for ethical reasons. Also, EGF was not tested as a solo material on the perforations, as the margins would not be raw then and the two groups would not be comparable.

EGF was selected because its critical role in the wound healing process was identified, and its receptors were detected in various animal tympanic membranes previously. ${ }^{2}$ It is commonly used to heal diabetic ulcers on the foot $^{3}$ and other parts of the body. It is, however, heat labile and requires transportation in cold chain that limits its extensive use.

In a study conducted by Kwon et $\mathrm{al}^{4}$ to investigate the effect of topical application of EGF ointment on the rate of wound healing and skin reepithelialization in a rat full-thickness wound model, they found that topical application of EGF accelerated the wound healing by myofibroblast proliferation and collagen synthesis. They applied EGF ointment on artificially created fresh wounds over rats, and the rate of wound healing was measured. There was significantly enhanced wound closure from the 5th to 12th day compared with the control group. In this study too, the margins of the tympanic membrane were freshened using $\mathrm{AgNO}_{3}$, so that it could be compared with that of a fresh wound and the added advantage of EGF along with $\mathrm{AgNO}_{3}$ could also be studied in another arm.

\section{Conclusion}

EGF topical application in small nonhealing central tympanic perforations is safe, and it enhances the healing effect of chemical cautery. As the success rate with EGF is promising, it could be aptly considered as medical myringoplasty. This procedure being possible under topical anesthesia is an added advantage. This is particularly useful in developing nations where the incidence of perforation due to trauma and COM is high, and it is not practical to subject each one of these patients to surgery for want of resources and workforce. EGF could also be tried to improve upon the results of surgical myringoplasty in cases of larger tympanic perforations. Also, EGF could be used to treat residual perforations after surgical myringoplasty when the patient is unwilling to undergo a revision procedure. 
Table 2 Comparison with previous other studies

\begin{tabular}{|c|c|c|c|c|c|}
\hline Year & Author & $\begin{array}{l}\text { Experimental } \\
\text { group }\end{array}$ & Results & Conclusion & Remarks \\
\hline 2016 & Lou et $\mathrm{al}^{5}$ & 97 patients (RCT) & $\begin{array}{l}92 \% \text { healing in EGF } \\
\text { group and } 83 \% \text { in } \\
\text { controls }\end{array}$ & $\begin{array}{l}\text { Shorter perforation } \\
\text { closure time in EGF } \\
\text { group than observation } \\
\text { group }\end{array}$ & $\begin{array}{l}\text { Supports our study } \\
\text { Performed on traumatic } \\
\text { perforations only. Healing and } \\
\text { nonhealing perforations not } \\
\text { segregated }\end{array}$ \\
\hline 2016 & Zhengcai-Lou et al ${ }^{6}$ & 86 patients (RCT) & $\begin{array}{l}86.2 \% \text { closure in } \\
\text { EGF group, } 89.3 \% \\
\text { in bFGF, and } 72.4 \% \\
\text { in controls }\end{array}$ & $\begin{array}{l}\text { Both EGF and bFGF } \\
\text { can accelerate the } \\
\text { closure of human large } \\
\text { traumatic tympanic } \\
\text { perforations }\end{array}$ & $\begin{array}{l}\text { Supports our study } \\
\text { Performed on traumatic } \\
\text { perforations only. Healing and } \\
\text { nonhealing perforations not } \\
\text { segregated }\end{array}$ \\
\hline 2016 & Jian-Yang et $\mathrm{al}^{7}$ & $\begin{array}{l}120 \text { patients } \\
\text { Retrospective } \\
\text { study }\end{array}$ & $\begin{array}{l}93.5 \% \text { closure in } \\
\text { EGF group, } 92 \% \\
\text { in ofloxacin, and } \\
82.2 \% \text { in controls }\end{array}$ & $\begin{array}{l}\text { Both EGF and oflox- } \\
\text { acin drops had rapid } \\
\text { closure compared with } \\
\text { controls in human large } \\
\text { traumatic perforations }\end{array}$ & $\begin{array}{l}\text { Supports our study } \\
\text { Performed on traumatic } \\
\text { perforations only. Healing and } \\
\text { nonhealing perforations not } \\
\text { segregated }\end{array}$ \\
\hline 2010 & Santa Maria et al ${ }^{2}$ & 410 rats & $\begin{array}{l}\text { High levels of EGF } \\
\text { in injured TM }\end{array}$ & $\begin{array}{l}\text { EGF played an important } \\
\text { role in TM healing }\end{array}$ & Supports our study \\
\hline 2006 & Ramalho and Bento ${ }^{8}$ & 50 chinchillas & $\begin{array}{l}30 \% \text { healing in EGF } \\
\text { group }\end{array}$ & $\begin{array}{l}\text { EGF promoted } \\
\text { the healing of TM } \\
\text { perforations }\end{array}$ & Supports our study \\
\hline 1999 & Chauvin et $\mathrm{al}^{9}$ & 28 guinea pig & $\begin{array}{l}100 \% \text { healing in } \\
\text { EGF group }\end{array}$ & $\begin{array}{l}\text { EGF: the prime } \\
\text { candidate to promote } \\
\text { healing of TM } \\
\text { perforation }\end{array}$ & Supports our study \\
\hline 1995 & Dvorak et al ${ }^{10}$ & 17 chinchillas & 100\% healing & $\begin{array}{l}\text { Significant benefit with } \\
\text { EGF use }\end{array}$ & Supports our study \\
\hline 1995 & Ramsay et al ${ }^{11}$ & 17 patients & $\begin{array}{l}\text { Complete closure } \\
\text { in one patient } \\
\text { No significant } \\
\text { hearing gains }\end{array}$ & $\begin{array}{l}\text { Higher concentration, } \\
\text { prolonged treatment, } \\
\text { or stripping of edges } \\
\text { could improve hearing }\end{array}$ & $\begin{array}{l}\text { We used higher } \\
\text { concentration and stripping } \\
\text { of edges to achieve a better } \\
\text { healing }\end{array}$ \\
\hline
\end{tabular}

Abbreviations: bFGF, basic fibroblast growth factor; EGF, epidermal growth factor; RCT, randomized controlled trial; TM, tympanic membrane.

\section{References}

1 Altman DG, Schulz KF, Moher D, et al; CONSORT GROUP (Consolidated Standards of Reporting Trials). The revised CONSORT statement for reporting randomized trials: explanation and elaboration. Ann Intern Med 2001;134(8):663-694

2 Santa Maria PL, Redmond SL, Atlas MD, Ghassemifar R. The role of epidermal growth factor in the healing tympanic membrane following perforation in rats. J Mol Histol 2010;41(6):309-314

3 Tsang MW, Wong WK, Hung CS, et al. Human epidermal growth factor enhances healing of diabetic foot ulcers. Diabetes Care 2003;26(6):1856-1861

4 Kwon YB, Kim HW, Roh DH, et al. Topical application of epidermal growth factor accelerates wound healing by myofibroblast proliferation and collagen synthesis in rat. J Vet Sci 2006;7(2):105-109

5 Lou ZC, Yang J, Tang Y, Fu YH. Topical application of epidermal growth factor with no scaffold material on the healing of human traumatic tympanic membrane perforations. Clin Otolaryngol 2016;41(6):744-749

6 Zhengcai-Lou, Zihan-Lou, Yongmei-Tang . Comparative study on the effects of EGF and bFGF on the healing of human large traumatic perforations of the tympanic membrane. Laryngoscope 2016;126(1):E23-E28

7 Jian-Yang, Zi-Han-Lou, Yahui-Fu, Zheng-Cai-Lou . A retrospective study of EGF and ofloxacin drops in the healing of human large traumatic eardrum perforation. Am J Otolaryngol 2016;37(4):294-298

8 Ramalho JR, Bento RF. Healing of subacute tympanic membrane perforations in chinchillas treated with epidermal growth factor and pentoxifylline. Otol Neurotol 2006;27(5):720-727

9 Chauvin K, Bratton C, Parkins C. Healing large tympanic membrane perforations using hyaluronic acid, basic fibroblast growth factor, and epidermal growth factor. Otolaryngol Head Neck Surg 1999;121(1):43-47

10 Dvorak DW, Abbas G, Ali T, Stevenson S, Welling DB. Repair of chronic tympanic membrane perforations with long-term epidermal growth factor. Laryngoscope 1995;105(12 Pt 1): 1300-1304

11 Ramsay HA, Heikkonen EJ, Laurila PK. Effect of epidermal growth factor on tympanic membranes with chronic perforations: a clinical trial. Otolaryngol Head Neck Surg 1995;113(4):375-379 